\title{
ULTRASOUND GUIDED ERECTOR SPINAE PLANE BLOCK FOR INTRAOPERATIVE AND POSTOPERATIVE ANALGESIA FOR PARTIAL HIP ARTHROPLASTY IN A PATIENT WITH CHRONIC HEART FAILURE
}

\author{
A. Fucak Primc1, M. Župčić2, V. Sotošek Tokmadžić3, A. Protić4. \\ 1 Clinical Hospital Centre- University hospital Rijeka, Department of anesthesiology and intensive care medicine, Rijeka, Croatia. \\ 2Clinical Hospital Centre- University hospital Rijeka- Faculty of Medicine- University J.J. Strossmayer- Osijek, Department of anesthesiology \\ and intensive care medicine, Rijeka, Croatia. \\ 3Clinical Hospital Centre- University hospital Rijeka-Faculty of Meidicine- University of Rijeka, Department of anesthesiology and intensive \\ care medicine, Rijeka, Croatia. \\ 4Clinical Hospital Centre- University hospital Rijeka-Faculty of medicine- University of Rijeka, Department of anesthesiology and intensive \\ care medicine, Rijeka, Croatia.
}

\section{INTRODUCTION}

We present a complex patient which was not an adequate candidate for neuraxial anesthesia or general anesthesia alone, because of a high perioperative risk ,so we decided to perform the erector spinae plane block (ESPB), a novel interfacial block under ultrasound guidance at the level of L4 transversus process.

\section{METHODS}

A 78- year old woman, ASA III, with previous known congestive heart failure,arterial hypertension and aortic valve stenosis was scheduled for a partial right hip arthroplasty.

To perform the ESPB the patient was placed in a sitting position and a high frequency linear ultrasound probe was used at the L4 transverse process level which was visualised $4 \mathrm{~cm}$ laterally from the midline in the parasaggital plane and $25 \mathrm{ml}$ of $0,25 \%$ levobupivacaine was infiltrated between the erector spine muscle and the transverse process. The local anesthetic spread in the paravertebral space blocked the dorsal and the ventral rami of the thoracic and abdominal spinal nerves.

After the induction to general anesthesia with a minimal dose of sufentanyl,propofol and rocuronium,only sevoflurane maintainance was used

\section{RESULTS}

The surgery was performed without addional opiate analgesia,the patient was hemodynamically stabile and emerged without complications. Postoperative she did not require any further analgesia. After 12 hours she started experiencing pain requiring NSAILs.

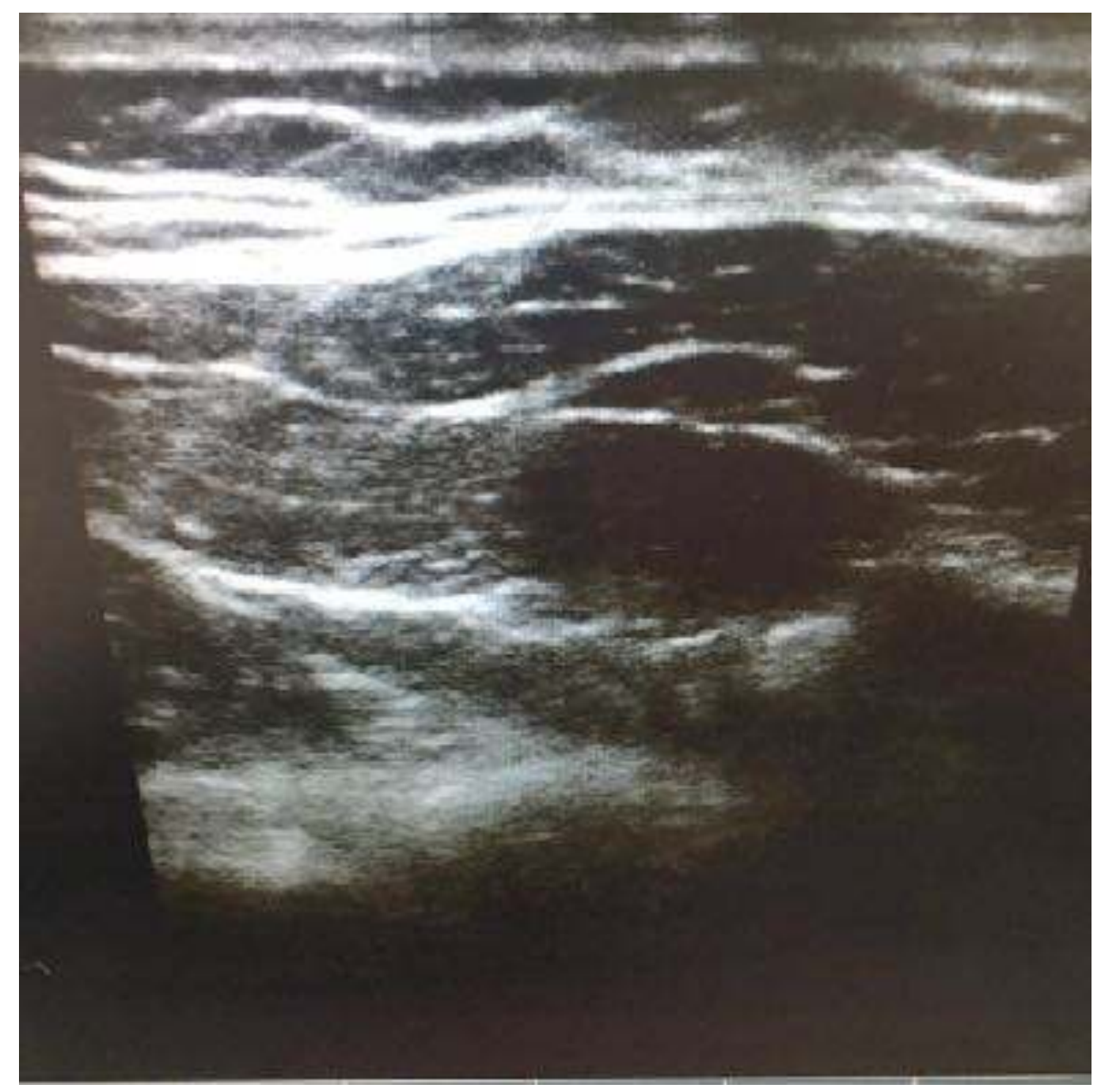

CONCLUSIONS:

The ESPB could be effective for intraoperative analgesia as for postoperative analgesia. Further studies need to be done to prove the local anesthetic spread and true benefit of the erector spinae plane block.

\section{References:}

1.Forero M, Adhikary SD, Lopez H, Tsui C, Chin KJ.,The Erector Spinae Plane Block: A Novel Analgesic Technique in Thoracic Neuropathic Pain.Reg Anesth Pain Med. 2016 SepOct:41(5):621-7

Picture 1: ultrasound anatomy of erector spine muscle and quadratus 